\title{
A QUESTÃO AGRÁRIA HOJE E OS DESAFIOS DO GOVERNO LULA
}

\section{Marta Inez Medeiros Marques}

Prof $^{\text {a do Dep. de Geografia e Coord }}{ }^{\mathrm{a}}$ do Lab. de Geografia Agrária Universidade de São Paulo - USP

\section{RESUMO:}

Este artigo tem como objetivo refletir sobre os desafios a serem enfrentados pelo Governo Lula na implementação de uma política de reforma agrária capaz de realizar o potencial de emancipação social que representa a democratização do acesso à terra no contexto da sociedade brasileira.

Visando ressaltar novas faces e elementos apresentados por esta problemática hoje, bem como melhor compreender seus traços estruturais, o texto faz um breve resgate histórico sobre a luta pela reforma agrária a partir de meados do século XX e analisa as ações do Estado voltadas para esta política desenvolvidas a partir de 1985.

Finalmente, após algumas considerações sobre as primeiras iniciativas do Governo Lula nesta área, são analisados quatro aspectos fundamentais relacionados à questão agrária que ele terá que enfrentar: (a) a situação da produção camponesa em face da abertura da economia brasileira; (b) as precárias condições das infra-estruturas produtiva e social nos assentamentos; (c) o caráter pontual e emergencial das ações de reforma agrária; (d) a manutenção de parcela significativa de nossa população rural, e não somente dela, na condição de cidadãos de segunda classe.

\section{PALAVRAS-CHAVE:}

Reforma agrária. Movimentos sociais, Estado, cidadania

\section{ABSTRACT}

This paper has the objective to think about the challenges to be faced by Lula's government to implement an agrarian reform policy able to fulfil the social emancipation potential which represents the land access democratization in the brazilian society context. 
Aiming to emphasize new faces and elements shown by this problem nowadays, as to a better understanding of its structural traces, this text makes a short historical retrospect about the struggle for the agrarian reform from mid-twentieth century on, and analyses the State actions in favor of this policy developed after 1985.

Finally, after some considerations about Lula's government first initiatives in this area, four fundamental aspects related to the agrarian question he will have to face are analysed: (a) the peasant production situation in its relation with brazilian economy opening; (b) the precarious conditions of productive and social infra-structure at the settlements; (c) the punctual and emergencial character of agrarian reform actions; (d) keeping a significant part of our country population, and not only of it, in a second-class citizens situation.

\section{KEYWORDS:}

Agrarian reform, Social movements, State, Agrarian policy, Citizenship.

\section{APRESENTAÇÃO}

Este texto tem como objetivo refletir sobre os desafios a serem enfrentados pelo Governo Lula para a definição e condução de políticas voltadas para a democratização do acesso à terra e a superação da questão agrária. Parte-se da idéia de que a manutenção, e mesmo intensificação, da extrema desigualdade na distribuição de terras no Brasil e a intensa exploração que marca as relações de trabalho dominantes no campo são responsáveis pela permanência e atualidade da questão agrária.

Por outro lado, a política de reforma agrária se mantém atual e ganha novos significados diante das mudanças sociais e econômicas em curso, que se caracterizam pelo crescimento do desemprego na cidade e no campo - apesar de uma pequena queda observada no desemprego urbano em 2004 -, bem como da crise urbana, com maior impacto sobre as classes subalternas.

Apesar da inegável relevância da questão agrária, o Estado brasileiro tem feito pouco para superá-la. Além do pequeno número de assentamentos rurais criados nas últimas décadas, em face do volume da demanda, destaca-se também a forma precária 
como estes vêm sendo implantados. Tais condições são agravadas pelos problemas que tradicionalmente afetam a produção camponesa no país, uma vez que as políticas públicas dirigidas ao campo têm privilegiado com freqüência a produção capitalista.

Porém, a consolidação do assentamento não se resume a uma problemática econômica, dependendo, dentre outros fatores, de como os assentados se organizam, estabelecem a sua inserção na sociedade local e o seu enraizamento na terra. A reforma agrária deve se inserir num projeto de desenvolvimento nacional, que tenha como um de seus objetivos a valorização do campo como espaço de vida, em que sejam asseguradas aos seus habitantes as oportunidades e comodidades da sociedade moderna.

O que também se espera de uma política como a reforma agrária é que ela possa gerar um impacto significativo sobre as relações de poder em vigor no campo brasileiro, superando a estrutura responsável pela manutenção de uma sociedade injusta e extremamente desigual.

A profunda desigualdade que marca a nossa sociedade não se reduz à sua dimensão econômica e, por isso, não pode ser tratada como sinônimo de carências materiais. Reflete uma sociedade segmentada, estratificada, na qual boa parte de seus membros é concebida e tratada como “cidadão de segunda classe”, ou mesmo “incivil”, não se constituindo cidadãos de direito. Dagnino (2000:82) chama nossa atenção para o fato de que, de acordo com a ordenação autoritária e hierárquica da sociedade brasileira, ser pobre significa não apenas privação econômica e material, mas também estar submetido a regras culturais que implicam uma completa falta de reconhecimento de sua condição de sujeito e portador de direitos.

A luta pela terra e o aprendizado dela decorrente, obtido pelos sem terra/assentados por meio da vivência dos embates políticos e das conquistas por eles alcançadas, representam os primeiros passos de um processo de emancipação social e política. Institui-se a partir daí uma nova forma de relação entre o Estado e este segmento do campesinato brasileiro, que passa a ter maior consciência de seus direitos. O próprio ato de criação do assentamento é acompanhado por um conjunto de medidas que formaliza o reconhecimento por parte do Estado de seu dever de assegurar o acesso a direitos básicos constitucionais que, apesar de celebrados como universais, não vêm sendo garantidos à totalidade de nossa população.

Assim, a expectativa de mudanças na relação entre Estado e sociedade desencadeada pelo acesso ao poder do Partido dos Trabalhadores, cuja atuação está historicamente relacionada à luta pela democratização da nossa sociedade, vem ao 
encontro do potencial de emancipação que se espera que apresente uma política de reforma agrária.

O texto abaixo se divide em três partes. Na primeira, é feito um breve resgate histórico sobre diferentes momentos em que a bandeira da reforma agrária ganha um apoio mais amplo no seio da sociedade nacional. Na segunda, é analisada a atuação do Estado brasileiro em relação à reforma agrária a partir de 1985. E, finalmente, na terceira parte, são identificados os principais desafios do Governo Lula em face da questão agrária.

\section{A LUTA PELA REFORMA AGRÁRIA EM TRÊS TEMPOS ${ }^{1}$}

O campo brasileiro tem sido marcado pela presença do latifúndio desde o período colonial, com amplas conseqüências para sua organização social e econômica e, sobretudo, para sua estrutura política. O grande proprietário tem desempenhado o papel de chefe político local desde o início em nossa formação social, atuando segundo uma lógica paternalista e clientelista, na qual a política é concebida e realizada como uma extensão da vida privada. A política aparece como “negócio privado” das elites e a participação das classes subalternas, como indesejada, devendo adequar-se aos interesses dos coronéis. Tal concepção autoritária e oligárquica da política atravessa os tempos, deixando fortes marcas na formação do Estado Brasileiro.

No entanto, é somente em meados do século passado que, com a mediação do Partido Comunista, os trabalhadores do campo levantam a bandeira da reforma agrária, contando com o apoio de segmentos da população urbana e a nossa desigual estrutura agrária passa, então, a ser vista como um problema pelo conjunto da sociedade. A partir daí, a reforma agrária tem ocupado lugar de destaque no debate político, assumindo significados diversos de acordo com o período histórico em questão.

Pode-se identificar três momentos distintos em que a reforma agrária torna-se uma reivindicação nacional:

nos anos 60 do século XX, juntamente com outras reformas de base reivindicadas pela sociedade, num cenário de crescente modernização da atividade agrícola e mudanças nas relações de trabalho.

1 Grande parte das considerações a seguir se baseiam nos seguintes trabalhos: Marques (2000), Medeiros (1989) e Oliveira (2001). 
em meados dos anos 80 do mesmo século, no início do primeiro governo civil após o período militar, quando são intensos os conflitos resultantes da expansão do capitalismo no campo e verifica-se a rearticulação das lutas que haviam sido reprimidas por ocasião do golpe militar de 1964.

no início nos anos 90, período em que o ideário neoliberal tem desencadeado um movimento de reestruturação produtiva com a eliminação de postos de trabalho no campo e na cidade, conferindo uma importância estratégica à reforma agrária como política de geração de empregos, o que parece estar mais claro para os movimentos sociais do que para o governo.

O processo de industrialização verificado nos anos 50 no país avança juntamente com a urbanização e o crescimento das cidades, apoiados em um forte êxodo rural. Neste momento, o campo brasileiro passa por uma série de mudanças no sentido da modernização de sua base técnica e de uma crescente exploração do trabalhador rural, com a ruptura de acordos em que se fundavam relações de produção tradicionais, como, por exemplo, a parceria e a relação de morada.

Crescem os conflitos no campo, fundam-se sindicatos de trabalhadores rurais (STR's) e formam-se as ligas camponesas em diferentes estados da federação. Ganha importância a luta pela extensão para o meio rural dos direitos assegurados pela legislação para os trabalhadores urbanos. A reforma agrária passa a ser defendida como pré-condição para o desenvolvimento do capitalismo, tendo em vista o seu potencial para atender a três objetivos: a redistribuição da riqueza e da renda (justiça social); a formação de um mercado interno (consolidação da industrialização) e a ruptura do poder político tradicional (democratização).

O ano de 1964 marca o início dos governos militares, período em que se assiste à repressão e à desorganização dos movimentos sociais e os sindicatos sofrem intervenção, assumindo um caráter marcadamente burocrático. O Estado, em aliança com o capital nacional e internacional, formula um projeto de desenvolvimento para o país centrado no objetivo de crescimento econômico e fortemente dependente de capitais externos. São adotadas políticas distintas para a área agrícola (econômica) e para a área agrária (social), aprofundando o processo de modernização em curso no campo e assegurando a estruturação dos complexos agroindustriais no país.

A modernização tecnológica da agricultura contribui para consolidar o processo de industrialização em andamento sem causar uma melhor distribuição da riqueza e do 
poder político no campo. No entanto, tais mudanças afetam o poder das oligarquias agrárias tradicionais ao promover a difusão de novas relações de produção e a desestruturação do contrato social que regia as relações sociais no interior das fazendas, além de estimular a territorialização do capital industrial e financeiro e ampliar a presença direta do Estado no campo.

O poder regulador do Estado cresce durante este período devido às transformações por ele sofridas enquanto máquina administrativa. Além de uma maior centralização do poder daí decorrente, o Estado passa a contar com uma legislação específica para o campo - o Estatuto do Trabalhador Rural (1963) e o Estatuto da Terra (1964) -, o que implica uma reordenação das relações entre os segmentos sociais aí encontrados e impõe um novo recorte da realidade ao criar categorias normativas para o uso do Estado e da sociedade como os conceitos de latifúndio, minifúndio, empresa rural etc. (Palmeira e Leite, 1998). São criadas instituições de pesquisa e extensão rural, além de institutos nacionais para o desenvolvimento rural e a reforma agrária, INDA e IBRA respectivamente ${ }^{2}$, visando apoiar as políticas de modernização e operacionalizar as propostas do Estatuto da Terra. É afirmada a inviolabilidade da empresa rural.

Nos anos 70, são elaborados o I e o II Plano Nacional de Desenvolvimento, que definem grandes obras de infra-estrutura para o país como a construção de usinas hidrelétricas, estabelecem políticas de incentivo à expansão de atividades agropecuárias de mineração em áreas de fronteira, propõem projetos de colonização para administrar as tensões sociais no campo etc.

Em decorrência do impacto dessas mudanças, verifica-se a progressiva retomada de iniciativas de organização dos trabalhadores com o aumento do poder de pressão destes. O sindicalismo se reestruturou sob a orquestração da Confederação Nacional dos Trabalhadores na Agricultura (CONTAG). A lei foi transformada em um campo de disputa e os sindicatos passam a fornecer assessoria jurídica. Em 1973, no II Congresso Nacional dos Trabalhadores Rurais, a defesa da reforma agrária é reafirmada em contraposição à política de colonização.

A ocupação das fronteiras baseada em grandes projetos apoiados em pesados subsídios estimulou o uso especulativo da terra, aumentando a concentração fundiária e agravando a questão agrária, com a reativação das lutas em nível local. O conflito rural passa a se centrar agora nas disputas entre grileiros, posseiros e entre estes e

\footnotetext{
${ }^{2}$ O Instituto Nacional de Colonização e Reforma Agrária (INCRA) nasce da fusão destes dois institutos em 1970.
} 
garimpeiros contra grupos indígenas. A violência crescente dos latifundiários parece se sustentar na certeza da impunidade, tendo em vista sua posição de aliados da repressão militar na manutenção da “ordem”.

À medida que os conflitos se avolumam e ganham maior dramaticidade fica evidente a fragilidade dos sindicatos como mediadores. Neste contexto, são criados o Conselho Indigenista Missionário (CIMI) em 1973 e a Comissão Pastoral da Terra (CPT) em 1975 e a Igreja passa a denunciar a violência, no campo, contra os indígenas e posseiros, e a lhes oferecer um serviço de articulação, assessoria e apoio à organização.

O envolvimento da Igreja nos conflitos do campo trouxe uma nova preocupação para o Estado, que percebe a capacidade desta instituição de articulação e de fundamentação ideológica das lutas que vinham acontecendo de forma dispersa. A noção do direito de se manter na terra e defender seu espaço social e cultural, seu território, é cada vez mais difundida entre indígenas e camponeses.

Em resposta a isto, procede-se à militarização da questão agrária com medidas como a criação do Grupo Executivo de Terras do Araguaia-Tocantins (GETAT) durante o governo Geisel e a nomeação de um general ligado ao Conselho de Segurança Nacional para o Ministério Extraordinário de Assuntos Fundiários (MEAF) em 1982.

A CPT expande o seu trabalho em favor de um "sindicalismo de base” e põe a terra como ponto central de sua atuação. Inicia-se o processo de abertura política visando, entre outras coisas, a reorientação da questão agrária para o âmbito partidário e a retirada de cena da Igreja.

O conflito pela terra em nossa história recente tem início com a destruição do mundo relacional da fazenda e projeta-se para fora dela na medida em que a grande propriedade ganha novos espaços nas áreas de fronteira, retornando para dentro dela, por meio das ocupações, quando a migração para outros espaços, rurais ou urbanos, não mais representa a possibilidade real ou virtual de melhoria de vida e acesso à cidadania social. Neste contexto, é reafirmada a importância da reforma agrária como meio para assegurar a inclusão social e produtiva de parcela significativa da população rural.

A luta pela reforma agrária é identificada, em nível nacional, com a luta pela justiça social e alcança amplo apoio popular. Na década de 80, a reforma agrária é reafirmada como um caminho para que os trabalhadores rurais sem terra atinjam a cidadania, inserindo-se no conjunto das lutas pela redemocratização do Estado brasileiro. 
Em 1984, é fundado o Movimento dos Trabalhadores Rurais Sem Terra (MST) durante o I Encontro Nacional dos Trabalhadores Rurais Sem Terra em Cascavel-PR, contando com a presença de representantes de dezesseis estados do país. No ano seguinte, o MST se estrutura como organização e torna-se um movimento social autônomo. Porém, somente nos anos 90, ele alcança efetiva projeção nacional, demonstrando grande poder de mobilização. Hoje, o movimento está organizado em quase todas as unidades da federação. ${ }^{3}$

No terceiro período enfocado, que tem início na década de 1990, a defesa da reforma agrária aparece justificada por novas questões. Não se trata mais de atender a uma demanda crescente de alimentos e matérias-primas e assegurar a formação de um mercado interno. Trata-se principalmente de gerar emprego e renda a custos mais baixos do que no meio urbano, além de permitir o acesso ao trabalho para um segmento da classe trabalhadora que, dada a sua baixa qualificação em face da atual demanda, dificilmente encontraria outra forma de inserção no mercado.

Muda a base social que hoje luta pela terra, reunindo-se sob a identidade de sem terra. Os segmentos sociais que emergem sob esta identidade são, além de trabalhadores de origem rural, trabalhadores pobres e desempregados da cidade que buscam assegurar uma vida e um trabalho dignos e proteger a família da desestruturação e das ameaças de violência enfrentadas nas periferias urbanas.

Torna-se, cada vez mais evidente, a convergência entre a demanda por terras e a demanda por habitação, saúde e educação, que constituem carências imediatas das famílias assentadas. A luta pela terra se apresenta como uma alternativa para pobres do campo e da cidade que têm ocupado historicamente uma posição subalterna em nossa sociedade, sendo tratados, em geral, como pessoas sem direitos ou como "cidadãos de segunda classe”.

A reforma agrária é hoje uma medida necessária para que ocorra uma "revolução social” no país com a ampliação das bases da cidadania para uma parte da população tradicionalmente excluída do direito a ter direitos.

\section{O ESTADO BRASILEIRO E A REFORMA AGRÁRIA}

\footnotetext{
${ }^{3}$ Sobre a origem do MST, seus objetivos e forma de organização, ver Stédile e Fernandes (1999).
} 
A ação do Estado em relação à questão agrária tem se caracterizado pela ambigüidade desde os anos 60 , refletindo a intensidade dos embates sociais verificados em torno do tema. Assim, apesar de sua relação histórica com as oligarquias agrárias, seja pelo fato de estas estarem diretamente representadas no poder, seja por meio de um Estado de compromisso, a sua atuação não pode ser analisada de forma linear, ignorando as contradições internas à sua estrutura e a complexidade que envolve esta problemática.

Com a restauração do regime civil em 1985, a política de reforma agrária é incluída no programa do novo governo. O Governo José Sarney (1985-1990), de base conservadora, é obrigado a reconhecer a gravidade da questão agrária em face das tensões sociais por ela geradas e cria o I Plano Nacional de Reforma Agrária (PNRA).

Verifica-se, então, uma mudança de ênfase da política de colonização para a de reforma agrária, com a criação de assentamentos de trabalhadores rurais, de preferência, nas regiões de origem destes, tendo o mecanismo da desapropriação por interesse social como principal forma de obtenção das terras. Porém, diante da forte oposição dos latifundiários, sobretudo daqueles que se organizam à frente da União Democrática Ruralista (UDR), e dos compromissos do Governo Sarney com sua base ruralista, não chegam a ser realizados $10 \%$ da meta do plano.

O Governo Fernando Henrique Cardoso (1995-2002) buscou a inserção do país na economia globalizada, segundo os parâmetros vigentes no mercado. Neste contexto, a reforma agrária não foi considerada medida prioritária. Esta política só foi incluída na agenda do Governo FHC porque o movimento social de luta pela terra e pela Reforma Agrária exerceu uma pressão crescente sobre o Estado, alcançou grande visibilidade e conquistou o apoio da opinião pública.

A ação do Governo FHC pode ser dividida em duas etapas distintas, que coincidem aproximadamente com o período de cada um de seus dois mandatos. Durante a primeira etapa, verificou-se um aumento significativo do número de desapropriações e de famílias assentadas, em que pesem as evidências de superestimação das estatísticas oficiais como é o caso da consideração de áreas de regularização fundiária como áreas de assentamento.

Foi nomeado um presidente para o INCRA com status de ministro e, mais tarde, recriado o Ministério Extraordinário de Política Fundiária. Foram encaminhados e aprovados no Congresso projetos de lei como os do Rito Sumário e da participação do Ministério Público em todas as etapas do processo de reforma, contribuindo para a 
aceleração das ações de desapropriação e para uma certa moralização da atividade da justiça nos conflitos agrários.

Para obter melhores índices de desempenho nesta área, o Estado priorizou o cumprimento de metas quantitativas, gerando situações caóticas como a existência de “assentamentos” onde as famílias aguardavam a demarcação dos lotes acampadas na terra desapropriada durante anos. ${ }^{4}$ Para efeito de contabilidade, essas famílias eram consideradas devidamente assentadas pelo governo.

Uma vez instalado, a luta continua para o ex-sem-terra. Não são criadas condições institucionais e financeiras suficientes para uma real estruturação dos assentamentos e de seus sistemas produtivos. O Estado distribui terras, mas não investe recursos necessários num planejamento de longo prazo, revelando o papel periférico atribuído às ações de reforma agrária pelo Governo FHC. ${ }^{5}$

Os movimentos sociais reivindicam cada vez mais melhores condições para os assentados, alcançando algumas conquistas importantes, apesar de sua abrangência limitada, como a reestruturação e ampliação do Programa Especial de Crédito para a Reforma Agrária (PROCERA) e a criação de um programa de assistência técnica especial para as áreas de assentamento denominado Projeto LUMIAR. ${ }^{6}$

Em seu primeiro mandato, o Governo FHC se vê acuado por uma onda crescente de manifestações e reivindicações e se envolve em duas tragédias de repercussão internacional, o massacre de Corumbiara em 9/8/1995 e o massacre de Eldorado de Carajás em 17/4/1997, quando muitos trabalhadores sem terra morrem em conflito com forças policiais. Estas ocorrências, em pleno período de normalidade democrática, são reveladoras de uma tendência crescente do Estado, no período, de enfrentamento dos conflitos relacionados à questão agrária pelas vias judicial e policial, em lugar da via política.

No início do segundo mandato, em 1999, o Governo FHC muda a sua atuação no campo e busca inserir os assentados no universo mais amplo da "agricultura familiar”. A estruturação econômica dos Projetos de Assentamento é assumida no discurso como prioritária, com o objetivo de evitar que a situação de dependência do INCRA se prolongue por tempo indeterminado. O governo alega ser necessário investir na profissionalização do assentado visando à aceleração de sua emancipação.

\footnotetext{
${ }^{4}$ Segundo depoimentos de técnicos do INCRA em maio/2000.

${ }^{5}$ Sobre uma análise crítica em relação à ação do Estado em áreas de assentamento, ver Bergamasco e Ferrante (1998).

${ }^{6}$ Criado em 1997 e desativado, dois anos depois.
} 
É lançado o programa “Novo Mundo Rural” que tem como objetivo declarado transformar o produtor familiar, assentado ou não, em um empreendedor integrado ao mercado em bases competitivas. Na prática, são adotadas as seguintes medidas:

extinção do PROCERA, que é substituído por uma linha de crédito do Programa Nacional de Fortalecimento da Agricultura Familiar (PRONAF), implicando uma redução dos recursos destinados aos assentados e a limitação do tempo em que eles têm direito a crédito em condições diferenciadas;

descentralização da reforma agrária, com a transferência de responsabilidades e de ônus financeiro e político para os outros níveis de governo; criação do "Banco da Terra”, programa que visa "reduzir" a ênfase na desapropriação por meio do financiamento direto da compra de terras "produtivas” por trabalhadores organizados em associações, com a intermediação dos estados.

A reforma agrária via mercado instituída pelo "Banco da Terra”, foi proposta supostamente para conter a "indústria de desapropriação" que tem sido beneficiada por indenizações milionárias, põe em segundo plano o instituto da função social da terra e reafirma na prática a precedência do direito da propriedade privada. Assim, o governo mantém o seu compromisso com a estrutura de poder econômico e político que historicamente tem impedido a distribuição da terra e da renda no país.

Na realidade, o anúncio do “Novo Mundo Rural” visava promover o esvaziamento do poder dos movimentos sociais sobre o processo de reforma agrária e um maior enquadramento desta política à lógica de livre mercado. Ele também representou a submissão da política agrária aos ajustes impostos ao governo pelos organismos internacionais frente à crise do Real em 1998.

Os assentamentos continuaram sem o apoio institucional e financeiro necessário para sua real estruturação, evidenciando claramente a inexistência de fato de um plano de desenvolvimento rural integrado às ações de distribuição de terras promovidas pelo governo federal.

\section{O GOVERNO LULA E A QUESTÃO AGRÁRIA}

Logo que assumiu o Governo, Lula se deparou com uma forte expectativa popular em torno de mudanças sociais, dentre elas a redistribuição da propriedade da terra no campo. Como medida inicial em relação a essa questão, são escolhidas pessoas 
ligadas aos movimentos sociais para ocupar cargos importantes na estrutura do INCRA e do Ministério do Desenvolvimento Agrário. Contudo, o governo tem dificuldade em pôr a máquina do Estado para funcionar e assenta somente cerca de 60 mil famílias em seu primeiro ano de mandato.

O II Plano Nacional de Reforma Agrária é lançado em novembro de 2003, com a meta de assentar 400 mil famílias até 2006 e proporcionar o acesso à terra a mais 130 mil famílias, via Programa Nacional de Crédito Fundiário (antigo Banco da Terra). O Plano prevê a definição de um novo modelo de assentamento, baseado numa maior participação popular e na articulação entre os níveis de governo - federal, estadual e municipal - e introduz o conceito de Desenvolvimento Territorial, que visa reconhecer a necessidade de ajustar a realidade de cada assentamento às características da região onde se encontra.

A seguir serão analisados quatro aspectos que pesam direta ou indiretamente na resolução da questão agrária hoje, ponderando-se sobre suas soluções possíveis e os passos que podem e devem ser dados pelo Governo Lula neste sentido. Como se verá abaixo, foram indicadas questões de ordens diversas, porém, convergentes e intimamente relacionadas entre si.

A)

A crescente instabilidade e fragilidade da produção dos assentados e dos camponeses em geral em face do avanço do processo de abertura da economia brasileira e aprofundamento da lógica de mercado.

A agricultura brasileira hoje é caracterizada pela ampla modernização e tecnificação de seu segmento mais capitalizado, com o crescimento da produtividade e aumento de sua competitividade no mercado internacional. Neste cenário, além da redução do emprego decorrente do movimento de reestruturação produtiva, verifica-se uma tendência de baixa dos preços agrícolas. Esse fato tem afetado em muito a produção camponesa e, em especial, a produção dos assentados, que geralmente trabalham com base em outro nível tecnológico e escala de produção mais reduzida. Assim, para se criarem postos de trabalho de maneira sustentável via reforma agrária, é preciso conceber e efetivar políticas destinadas especificamente para o fortalecimento da produção camponesa.

Caberia, portanto, ao governo adotar as seguintes medidas: o investimento em pesquisas voltadas para o desenvolvimento de tecnologia adequada a esta forma de organização da produção; a ampliação e capacitação de um quadro técnico voltado para 
o atendimento deste público; a oferta de cursos direcionados à formação profissional dos agricultores; o estímulo e apoio à estruturação de mecanismos de crédito especiais, como é o caso das experiências de crédito solidário; o estímulo à organização de estruturas associativas visando a armazenagem e a comercialização coletiva da produção; o desenvolvimento de políticas que favoreçam direta ou indiretamente a comercialização da produção camponesa, seja pela regulação do mercado de certos produtos, seja pela aquisição de produtos agrícolas para o abastecimento de escolas públicas, hospitais, quartéis etc.

As formulações sobre desenvolvimento rural que têm surgido apresentam, em geral, marcado enfoque mercadológico, estimulando os produtores familiares a uma busca incessante de nichos de mercado e de vantagens comparativas. Supõe-se que estes estejam munidos das mesmas armas e movidos pelos mesmos objetivos que o empresário capitalista que tem a atividade agrícola como um negócio. Ignora-se que suas armas são poucas e frágeis em face dos outros segmentos atuantes nos complexos agroindustriais, em muitos casos, representantes do capital monopolista.

A situação de relativo isolamento que prevalece em grande parte das "áreas reformadas” constitui terreno fértil para o domínio monopolista de diferentes formas de capital. Assim, vê-se claramente o quanto é importante a organização dos produtores e a constituição de redes de apoio constituídas por movimentos sociais, associações, além instituições do Estado em seus vários níveis.

Um dos grandes desafios deste governo é superar o horizonte estabelecido pela ideologia neoliberal que tem penetrado o pensamento e a gestão pública e, no caso específico das ações de reforma agrária e das políticas dirigidas ao campo, tem resultado na adoção do conceito de “agricultura familiar”, que vê o pequeno produtor camponês como um empreendedor com apenas algumas poucas diferenças em relação ao “agricultor patronal”.

A construção de alternativas econômicas não prescinde da organização política e social dos assentados e produtores familiares em geral. É preciso considerar que há sempre uma relação de poder na forma como se estruturam as relações de produção e de mercado.

Por outro lado, a controversa territorialização de grande parte de nossa elite proprietária de terras, apoiada em processos altamente especulativos e fraudulentos, indica, na prática, os limites na aplicação da lei e as deficiências da atuação do Estado em relação ao mercado de terras. 
Ao não levar em consideração a situação de classe ou condição social do agricultor camponês, o Estado ignora diferentes formas de subordinação e expropriação da renda a que estes produtores vêm sendo historicamente submetidos. Desta forma, o Estado não reconhece devidamente o papel de regulação das relações que envolvem este segmento social e os mercados de terra e de produtos agrícolas que caberia a ele desempenhar.

B)

A precariedade das infra-estruturas produtivas e sociais nas áreas de assentamento.

O assentamento deve ser concebido como um espaço de vida e de reprodução da família. A área de assentamento deve apresentar, além de boas condições de produção, todos os serviços necessários a uma vida digna para a comunidade de assentados.

Cabe ao Governo Lula conceber o assentamento como um espaço de cidadania, no qual o direito a uma ocupação aparece como um dos direitos básicos do cidadão, devendo ser acompanhado pelos direitos à moradia, à saúde e à educação. A elaboração e implementação de políticas que superem o marco assistencialista de programas como Fome Zero e renda mínima aparecem como um grande desafio para este governo. O cidadão não pode ser reduzido à condição de consumidor, de alguém cuja integração social depende apenas do acesso a uma renda monetária.

C) $\quad \underline{O}$ caráter pontual e emergencial que tem caracterizado a condução da reforma agrária desde a elaboração do I PNRA em 1985.

Visando superar essa situação, faz-se necessária a elaboração de um projeto de desenvolvimento nacional, no qual a reforma agrária assuma um papel de relevância e se insira num conjunto de metas estratégicas definidas para o campo.

Cabe ao governo Lula ir gestando este projeto e traçando suas grandes linhas juntamente com a sociedade organizada e, ao mesmo tempo, ir tecendo as alianças que lhe darão sustentação e adequando a máquina do Estado para sua execução. Só assim, o Estado poderá superar a polarização de interesses entre os trabalhadores sem terra e a classe dos grandes proprietários de terras.

D) $\quad$ A manutenção de parcela significativa de nossa população rural, mas não apenas dela, na condição de cidadãos de segunda classe. 
Desde o Governo Sarney, a reforma agrária passa a ser defendida sobretudo como um caminho para se garantir o acesso à cidadania para grande parte de nossa população rural.

É preciso que sejam superadas as relações de dependência política que ainda hoje se reproduzem no campo brasileiro, evitando-se seu mero deslocamento para novos contextos, como a relação com os movimentos sociais ou com o Estado. Para isso, é preciso favorecer a participação da sociedade civil nos processos decisórios por meio da ampliação de mecanismos institucionais de articulação entre o Estado e a sociedade.

Para que uma política de reforma agrária gere resultados duráveis no tempo, ela deve ser concebida como o primeiro passo de uma longa caminhada. Faz-se necessário o esforço continuado para a construção de alternativas que apontem no sentido da emancipação social e política dos assentados, para que eles não se tornem “clientes” da reforma agrária, mas conquistem novos direitos e a garantia de cumprimento destes. Este processo não pode prescindir da luta política.

O Governo Lula pode assim contribuir para a disseminação de uma nova cultura política no campo. Neste sentido, ele deveria evitar o “aparelhamento” do Estado, que trunca o processo de constituição do tecido democrático, na medida em que enfraquece e esvazia de sentido outros níveis institucionais, cujo fortalecimento seria fundamental para assegurar a continuidade da participação social nos processos políticos para além do tempo de um governo. A suposta possível identificação direta entre o Estado e a sociedade representa, na verdade, um risco de constituição de um poder autoritário. É papel do Estado arbitrar sobre ganhos e impor perdas, portanto, administrar conflitos e disputas de interesses existentes no seio de uma sociedade.

O Governo Lula, sustentado por um partido originariamente de esquerda, de conhecido compromisso histórico com a bandeira da reforma agrária, tem se portado como se esta política já não tivesse mais a mesma importância de outrora. Semelhante ao Governo FHC, tem buscado ampliar o número de famílias atendidas por programas de caráter predominantemente assistencialista como o renda mínima e o Fome Zero, em detrimento de uma atuação firme visando a efetiva inserção social da população mais pobre. 
Do "Estado desenvolvimentista", grande empreendedor voltado para o projeto de transformação do país numa grande potência econômica, na qual a inclusão social se daria como decorrência natural do processo, passamos ao "Estado Mínimo”, ao qual cabe o papel de administrar a exclusão em diferentes níveis, entendida como custo social inevitável dos processos de modernização e globalização. É desafio deste governo forjar uma alternativa a estas perspectivas sem cair em armadilhas salvacionistas. O caminho não está pronto, é preciso que o Estado assuma a liderança em sua construção.

Talvez o maior desafio do Governo Lula é estar à altura do momento histórico atual, em que temos uma conjuntura favorável à reforma agrária pela situação de relativa baixa de preços em que hoje se encontra o mercado de terras em grande parte das regiões do país, pela pressão dos movimentos sociais em luta pela terra e apoio da opinião pública, pela necessidade de serem criados postos de trabalho e o baixo custo que esta medida representa no contexto da reforma agrária.

É preciso que sejam definidas áreas prioritárias para a reforma agrária, conforme está previsto no Estatuto da Terra, e era defendido por José Gomes da Silva, histórico defensor da reforma agrária no país ${ }^{7}$. Resultados de pesquisa recente desenvolvida pelo CPDA em conjunto com o Museu Nacional do Rio de Janeiro que avaliou os impactos dos assentamentos rurais em regiões onde eles foram implantados de forma concentrada, comprovam as vantagens desta orientação ${ }^{8}$.

A defesa da idéia de desenvolvimento territorial adotada pelo II PNRA e toda a contribuição que autores como Abramovay (2000 e 2003) e Veiga (2000 e 2001) vêm dando a este respeito constituem um avanço para a discussão sobre desenvolvimento rural ao chamar atenção para a necessidade de levarmos em conta as especificidades do território. “A idéia central é que o território é mais que simples base física para as relações entre indivíduos e empresas, possui um tecido social, uma organização complexa feita por laços que vão muito além de seus atributos naturais e dos custos de transportes e de comunicação. Um território representa uma trama de relações com raízes históricas, configurações políticas e identidades que desempenham um papel pouco conhecido no próprio desenvolvimento econômico (Abramovay, 2000:304).”

\footnotetext{
7 José Gomes da Silva foi um histórico defensor da reforma agrária no Brasil. Participou da implantação do "Projeto Revisão Agrária" do Governo Carvalho Pinto em São Paulo no início da década de 1960. Desde então, envolveu-se na luta em favor da reforma agrária, tendo sido presidente da Associação Brasileira de Reforma Agrária (ABRA) nos anos 80 e presidente do INCRA no início do Governo Sarney, dentre outros cargos de semelhante relevância.

${ }^{8}$ Ver Leite, Heredia et al., 2004.
} 
Contudo, a discussão sobre desenvolvimento territorial tem se restringido à perspectiva econômica, resultando na adoção de um discurso liberal em favor da mobilização e valorização de potencialidades locais. Neste sentido, pouca importância é dada ao conteúdo político do território, como espaço de reprodução de uma determinada estrutura de poder - que se constitui, em grande parte do campo brasileiro, a partir do controle de grandes extensões de terras.

Outra importante questão que parece estar sendo esquecida por esta perspectiva é a da necessária construção de um projeto de desenvolvimento em escala nacional que considere as necessidades da população rural, juntamente com as potencialidades do campo, e o inegável conteúdo político aí envolvido. A análise não pode assim perder de vista o estrutural em favor do conjuntural.

\section{Bibliografia:}

ABRAMOVAY, Ricardo. "O capital social dos territórios: repensando o desenvolvimento rural.” In: LEITE, Pedro S. et al. (orgs.), Reforma agrária e desenvolvimento sustentável. Brasília, Paralelo 15 / NEAD / Ministério do Desenvolvimento Agrário, 2000.

O futuro das regiões rurais. Porto Alegre, Ed. Universidade UFRGS, 2003.

BERGAMASCO, Sonia e FERRANTE, Vera Lúcia S. B. “No reino da modernização: o que os números da reforma agrária (não) revelam.” In: MARINHO, Danilo N. C. e ROSA, Sueli L. C., Os assentamentos de reforma agrária no Brasil. Brasília, Editora Universidade de Brasília, 1998.

DAGNINO, Evelina. “Cultura, cidadania e democracia: a transformação dos discursos e práticas na esquerda latino-americana.” In: ALVAREZ, Sonia E., DAGNINO, Evelina, ESCOBAR, Arturo (orgs.), Cultura e política nos movimentos sociais latinoamericanos: novas leituras. Belo Horizonte, Ed. UFMG, 2000. 
LEITE, Sérgio, HEREDIA, Beatriz et al. (coords.). Impactos dos Assentamentos: Um Estudo sobre o Meio Rural Brasileiro. Brasília, IICA/ NEAD; São Paulo, Ed. UNESP, 2004.

MARQUES, Marta Inez M. De sem-terra a 'posseiro', a luta pela terra e a construção do território camponês no espaço da Reforma Agrária: o caso dos assentados nas Fazendas Retiro e Velho - GO. São Paulo, Depto. de Geografia da USP, 2000. (tese de doutorado)

MEDEIROS, Leonilde S. de. História dos movimentos sociais no campo. Rio de Janeiro, FASE, 1989.

OLIVEIRA, Ariovaldo U. de . "A longa marcha do campesinato brasileiro: movimentos sociais, conflitos e reforma agrária.” Estudos Avançados, São Paulo, v. 15 , n 43, pp. 185-206, set/dez 2001.

PALMEIRA, Moacir e LEITE, Sérgio. "Debates econômicos, processos sociais e lutas políticas.” In: Costa, Luiz Flávio C. e Santos, Raimundo, Política e Reforma Agrária. Rio de Janeiro, Mauad, 1998.

STÉDILE, João Pedro e FERNANDES, Bernardo M. Brava gente: a trajetória do MST e a luta pela terra no Brasil. São Paulo, Fundação Perseu Abramo, 1999.

VEIGA, José E. da. A face rural do desenvolvimento; natureza, território e agricultura. Porto Alegre, Ed. Universidade UFRGS, 2000.

. “O Brasil rural ainda não encontrou seu eixo de desenvolvimento.” Estudos Avançados, São Paulo, v. 15 , nº 43, pp. 101-119, set/dez 2001. 